\title{
The use of diffuse laser photonic energy and indocyanine green photosensitiser as an adjunct to periodontal therapy
}

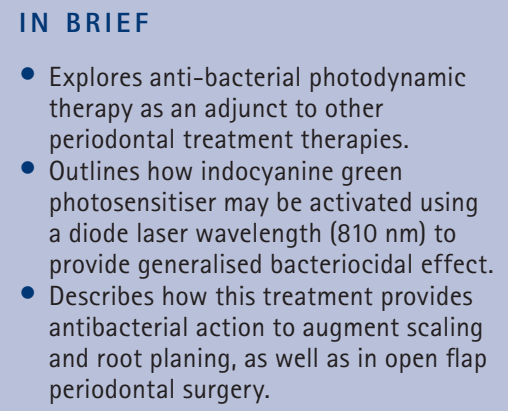

- Explores anti-bacterial photodynamic therapy as an adjunct to other periodontal treatment therapies. Outlines how indocyanine green photosensitiser may be activated using a diode laser wavelength $(810 \mathrm{~nm})$ to rovide generalised bacteriocidal effect. Describes how this treatment provides and root planing, as well as in open flap periodontal surgery.

\section{S. Parker ${ }^{1}$}

\section{VERIFIABLE CPD PAPER}

\begin{abstract}
Light-activated chemical therapy - generally known as photodynamic therapy (PDT) - has been developed within medicine, to allow the use of an applied agent (photosensitiser) that could be activated using laser photonic energy, leading to the destruction of target cellular structures. In clinical dentistry, PDT has been utilised within a wide scope of topical application in endodontic, periodontal and oral epithelial pathology where specifically, anti-bacterial action may prove useful. Underlying the complex and multi-factorial aetiology, periodontal disease remains of essentially-bacterial origin and anti-bacterial PDT (aPDT) has been investigated as an adjunctive to other periodontal treatment therapies. Of several topically-applied photosensitisers, one agent, indocyanine green, may be activated using a diode laser wavelength $(810 \mathrm{~nm})$ that is commonly-available in clinical dental practice, to provide generalised bacteriocidal effect. Unlike antibiotics and antibacterial mouthwashes, the mode of action appears to be nonspecific to bacterial species and is linked to cell death through a process of oxidative stress. Additionally, indocyanine green has otherwise low toxicity to non-target host tissue and dental restorative materials. This paper explores the background to this therapy, its position within the broader delivery of periodontal treatment and the specific application of indocyanine green in clinical dental practice.
\end{abstract}

\section{PHOTOSENSITISER - ELECTRON TRANSFER AND REACTIVE OXYGEN SPECIES}

The concept of photodynamic therapy (PDT) is based on the use of photosensitising chemicals that preferentially accumulate in target cells. These cells may be eukaryotic, neoplastic or non-host (prokaryotic), such as bacteria. ${ }^{1}$

The ideal PDT photosensitiser should absorb light of wavelengths that fall within the visible-red and near-infrared region of the electromagnetic spectrum (approximately 650-900 nm), known as 'the therapeutic window', where maximal penetration of light into tissues is observed. ${ }^{2}$

A photosensitiser is a chemical compound that readily undergoes photoexcitation and then transfers its energy

'Dental Surgeon, 30, East Parade, Harrogate, HG1 5LT, UK

Correspondence to: Dr Steven Parker

Email: thewholetooth@easynet.co.uk

\section{Refereed Paper}

Accepted 3 June 2013

DOI: 10.1038/sj.bdj.2013.790

${ }^{\circledR}$ British Dental Journal 2013; 215: 167-171 to other molecules. ${ }^{3}$ Usually, the photosensitiser is excited from a ground singlet state (quantum state with zero spin angular momentum) to an excited singlet state. It then undergoes inter-system crossing to a longer-lived, excited, triplet state. When the photosensitiser and an oxygen molecule are in close proximity, an energy transfer can take place that allows the photosensitiser to relax to its ground singlet state and induce an excited singletstate oxygen molecule. Singlet oxygen is an aggressive chemical species and will very rapidly react with any nearby biomolecules. ${ }^{4}$ Ultimately, these destructive reactions will kill cells through apoptosis or necrosis. ${ }^{5}$ There are more than 400 compounds that have been shown to exhibit photosensitising properties, either in vitro or in vivo. ${ }^{6}$

Singlet ('nascent') oxygen is the common name used for each of the two metastable states of molecular oxygen $\left(\mathrm{O}_{2}\right)$ with higher energy than the ground state triplet oxygen. It may also be referred to as reactive oxygen species (ROS). Of most importance in elective photodynamic cytotoxicity is the first triplet state (singlet) oxygen. Its presence in close proximity with the target cellular structure induces oxidative stress - an imbalance between the production of reactive oxygen and a biological system's ability to readily detoxify such reactive intermediates. ${ }^{7}$ Such interaction is extremely rapid, as the effectiveness of ROS is approximately $4 \mu \mathrm{sec}$ in water and $20 \mu \mathrm{sec}$ in cell membranes. The results of induced oxidative stress in target cells may include the following: 8,9

- Crosslinking of bacterial membrane lipids

- Destruction of protein and ion channels

- Elimination of critical metabolic enzymes

- Cell agglutination

- Inhibition of release of collagenase and protease.

\section{INDOCYANINE GREEN}

Indocyanine green (ICG) is a tri-carbocyanine that belongs to the large family of cyanine dyes. ${ }^{10}$ The ICG molecule exhibits a molecular structure with amphiphilic properties that has both hydrophilic and lipophilic 
properties. Through photon-induced electron transfer, ICG is able to produce powerful photosensitized cellular damage. ${ }^{11,12}$

Pharmaceutically, it is supplied as a stable dry (tablet) form, which is readily soluble in water $(1 \mathrm{mg} / \mathrm{mL})$. In dispersed soluble form, ICG binds to cellular lipoproteins and when exposed to laser photonic energy $(<200 \mathrm{~mW})$, with optimal peak absorption at 805-810 $\mathrm{nm}$ near-infrared wavelength. These wavelengths have more capacity to penetrate biological tissue than rest of the spectrum. Penetration depth in biological tissue for visible-red wavelengths $(650 \mathrm{~nm})$ is $3-3.5 \mathrm{~mm}$, whereas for near-infrared light (800-1,100 nm) it reaches up to $6 \mathrm{~mm}^{13}$

ICG has proven effectiveness as a lightactivated antibacterial agent, for adjunctive use in wound healing ${ }^{14}$ or treating chronic infections of mucous membranes and skin. ${ }^{15-18}$ When photo-excited, ICG can induce the production of singlet oxygen with strongly cytotoxic activity. ${ }^{19}$

ICG in therapeutic concentrations has almost no host toxicity and is approved by the USA FDA for medical applications. ${ }^{20}$ It has been investigated for use in bacterial infections ${ }^{21,22}$ and within the treatment of antibiotic resistant bacterial pathogens, ICG has been investigated against selected bacterial species (S. aureus and P. aeruginosa) in vitro, providing statistically-significant reduction in bacteria of 95-99\%, depending on fluence values. ${ }^{23}$

The introduction of isocyanine green as a photosensitiser in adjunctive periodontal therapy is recent and coincides with the development of low-level operating parameters for dental Diode laser machines and the adoption of a PDT within periodontal treatment. ${ }^{24-26}$

\section{LASER USE IN ADDRESSING PERIODONTOPATHIC BACTERIAL POPULATION WITHIN THE GINGIVAL SULCUS.}

Laser use as an adjunct to the bacterial reduction in target tissue has largely advocated photonic energy at supra-ablation threshold values. ${ }^{27}$

With regard to the sole use of ablative laser energy in bactericidal effects, the following phenomena may be considered as limiting factors:

- Primary bactericidal action linked to absorption phenomena
- Primary interaction coaxial with the laser beam

- Risk of collateral damage associated with thermal rise and non-target absorption

- Other difficulties - access, limitations of delivery tip design, etc.

Conversely, the use of a non-ablation, low-level laser wavelength to initiate photodynamic antimicrobial chemotherapy in a suitably administered photosensitiser may be seen to have the following advantages over 'conventional' laser use: ${ }^{28}$

- Non-surgical (sub-ablative) photonic energy values employed

- Primary (indirect) interaction through chemical mediator (photosensitiser)

- The use of non-collimated light through a diffuser tip can overcome limited access and be further compensated by scatter through the body of the liquid sensitiser.

Little risk exists of collateral damage within confined target sites and photosensitisers should be used with caution and in specified dilute doses, to avoid possible toxicity. ${ }^{29}$

An increasing number of studies have been published that describe the effect on periodonto-pathogenic bacteria by photodynamic methods. These investigations have underlined the introduction of this laser-assisted modality into the practice of periodontology. ${ }^{30-34}$

The development and expansion of photodynamic therapy (PDT) into general dental practice has spawned the use of several acronyms and these include:

- PACT - photodynamic anti-microbial chemotherapy.

- PAD - photo-activated disinfection

- PDD - photodynamic disinfection

- aPDT - anti-microbial photodynamic therapy.

This latter acronym appears to reflect the least commercial association and its adoption is employed in this paper.

Local infections such as those that occur within the oral cavity may be potential targets for antibacterial photodynamic therapy. ${ }^{35-37}$ In addition to other mechanical debridement techniques, the supraand sub-gingival plaque biofilm on tooth

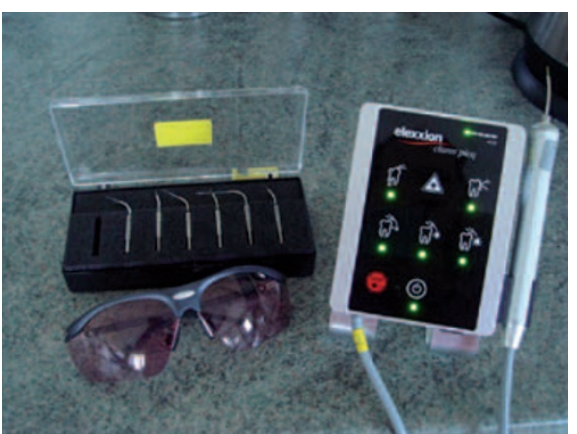

Fig. 1 Example of diode laser, delivering photonic energy of single $(810 \mathrm{~nm})$ wavelength. Elexxion AG Germany

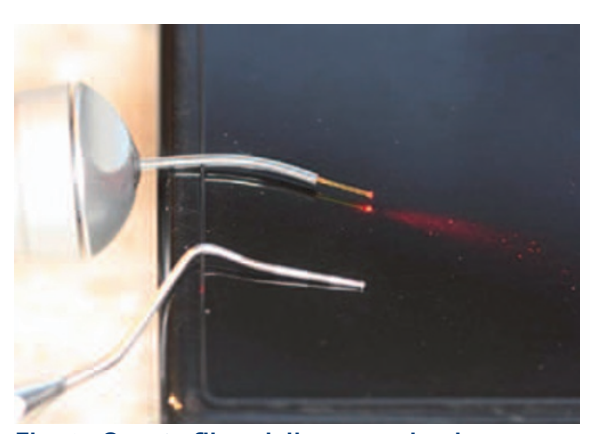

Fig. 2 Quartz fibre delivery mechanism (300 $\mu \mathrm{m}$ diameter) compared to periodontal probe instrument

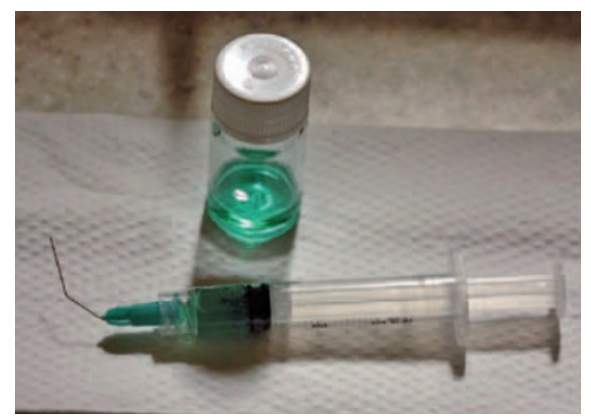

Fig. 3 Indocyanine green photosensitiser dissolved in sterile water and delivered to treatment sites using a blunt canula

surfaces is often easily accessible for flushing with the dye and activation with lowlevel laser light.

Notwithstanding anecdotal opinion, the benefits to be derived from the adjunctive use of aPDT in providing treatment of conditions of a bacterial origin may be summarised as follows:

- Straightforward clinical technique

- Non-surgical protocol required for application of photosensitiser

- Topical/systemic antibiotics not required

- Facilitates access into deep/limitedaccess sites (furcations, invaginations)

- Reduced need for surgery/direct flap approach 


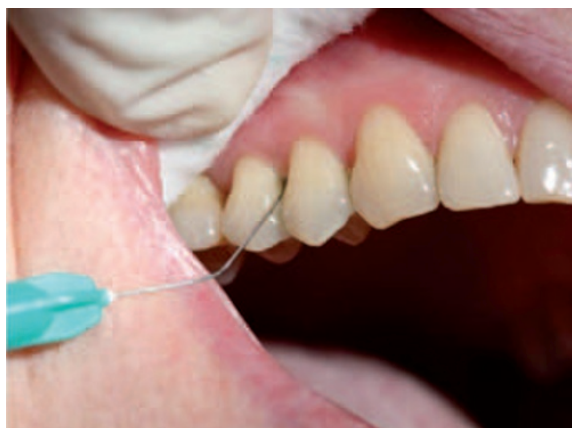

Fig. 4 Application of photosensitiser within periodontal pocket

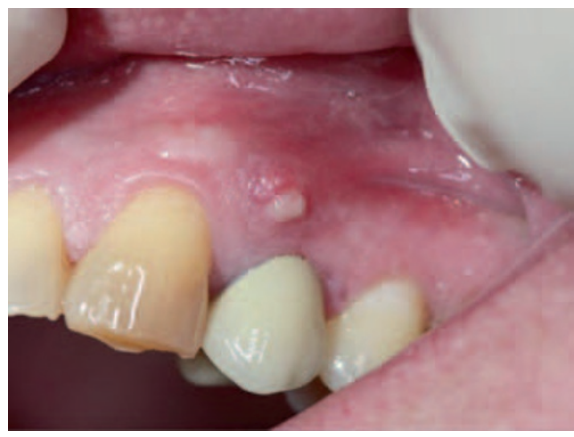

Fig. 7 Lateral sinus associated with periodontal lesion mesial UL first premolar tooth

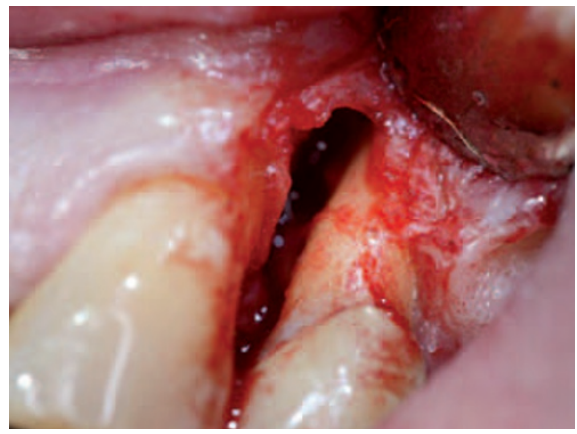

Fig. 10 Granulation tissue removed, root surface debrided

- Reduced risk of bacteraemia. Useful in patients with 'at-risk' medical history.

As an example of sub-ablative laser therapy, there may be possible added benefits with aPDT. Evidence exists as to the influence of low-level laser photonic energy on the healing processes in both soft and hard oral tissue. The development of understanding of the processes associated with photobiomodulation spans many decades and provides an insight into how tissue response can be modified, both generally and specifically with periodontal tissue. ${ }^{38-40}$

One study has reported that the use of low-level laser as an adjunct to scaling and root planing can lead to improved radiographic bone density. ${ }^{41}$ Guided bone regeneration techniques may be enhanced with low level lasers, and a meta-analysis of

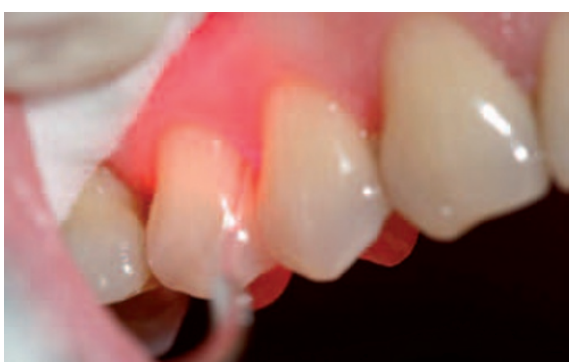

Fig. 5 Treatment site exposed to laser photonic energy. The $810 \mathrm{~nm}$ wavelength is invisible (near-IR) and a red light is used as a co-axial aiming beam

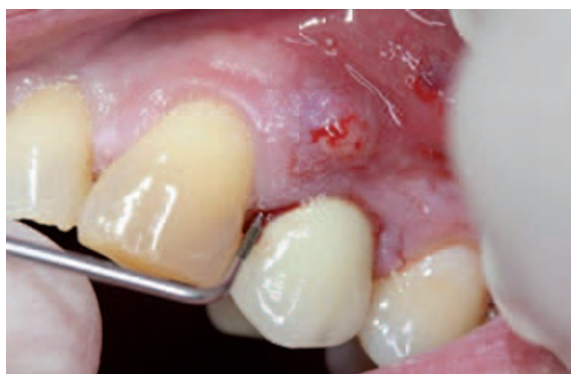

Fig. 8 Blunt-probe exploration of treatment site

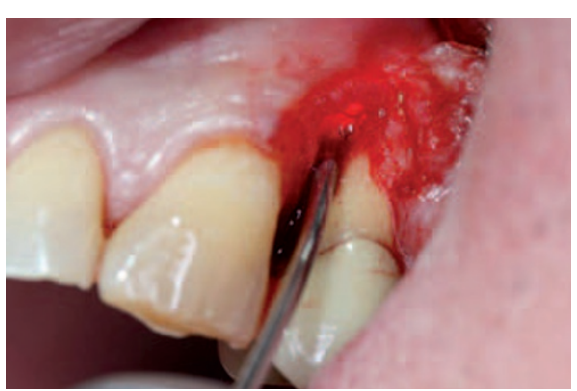

Fig. 11 Application of indocyanine green photosensitiser and exposure to $810 \mathrm{~nm}$ lowlevel laser. Adjunctive benefit of aPDT will help reduce periopathogen contamination of the surgical site

over 12 years of published data $(\mathrm{n}=800)$ supports this opinion ${ }^{42}$ and suggests that optimal fluence values of 85 Joules/sq cm may be required.

However, the fluence (energy density) levels associated with aPDT may be too low to breach the therapeutic threshold of bone biomodulation. Consequently, with osseous surgical periodontal repair, it is advisable to use higher fluence values to influence bone healing, ${ }^{43-45}$ than applicable to aPDT.

\section{CLINICAL APPLICATIONS}

A distinct disincentive to the uptake of laser use in clinical dentistry has been the often-misinformed belief that individual clinical procedures demand a separate laser machine. Certainly, the mixture of target cellular structures within oral soft

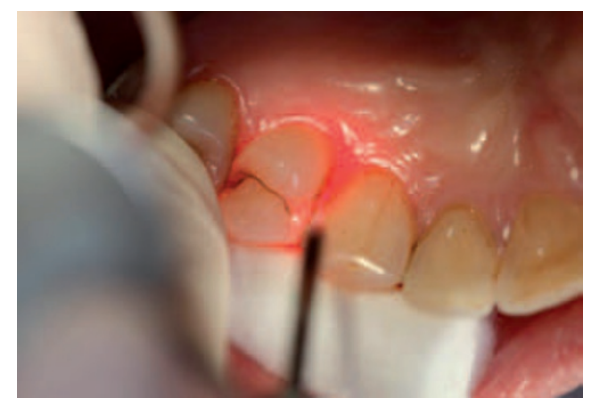

Fig. 6 Application of laser on palatal aspect of tooth. Note scatter of energy within tissue

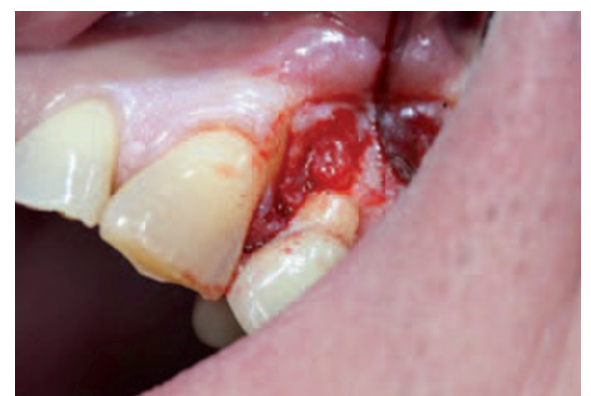

Fig. 9 Buccal mucoperiosteal flap raised under local anaesthetic. Interproximal bone loss and associated granulation tissue in situ

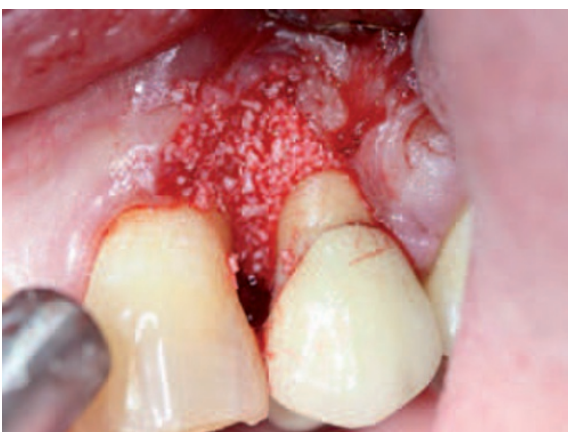

Fig. 12 Application of matrix graft mineral (Bio-oss. Geistlich Pharma AG., Germany)

and hard tissue places demands on broad choice of laser wavelength. However, the application of non-ablative, low-level laser photonic energy poses distinction more on the amount of light energy being delivered to the tissue. The advantage of the $810 \mathrm{~nm}$ laser is that it is manufactured using diode semi-conductor technology; as such the machine is small enough to be a portable desk-top unit and with suitable power-gating may be configured to enable laser use in both surgical and non-surgical therapy modes. This has advantage in providing a laser that can be used in soft tissue surgery as well as deliver low-energy stimulation of tissue (photobiomodulation) ${ }^{46,47}$ and activation of a photosensitiser in antibacterial chemotherapy (Figs 1, 2 and 3).

The isocyanine green photosensitiser is supplied as a tablet that is dissolved in a 
vial of sterile water. The prepared solution is sufficient for all-quadrant application per patient and should be administered to no more than a single quadrant at any time.

Following evaluation of selected periodontal pocket architecture in the area to be treated, the ICG solution is applied using a blunt, side-release cannula and a small amount of photosensitiser expelled into the pocket. The uptake of the chemical is rapid enough to allow immediate use of the laser in delivering photonic energy. The laser unit (Elexxion Claros Pico $810 \mathrm{~nm}$, Elexxion AG Germany) is configured by the manufacturer to deliver 20,000 light pulses $(\mathrm{Hz})$ each second. The pulse duration is fixed to $25 \mu$ s with a peak power of $200 \mathrm{~mW}$. That means that the laser is switched on 50\% of the time which results in an average power of $100 \mathrm{~mW}$ delivered through an optic fibre tip of $400 \mu \mathrm{m}$ diameter during a period of 30 seconds per treatment site; this provides a fluence (energy density) value of 0.0125 Joules/sq $\mathrm{cm}$ and 3.0 Joules of total energy delivered.

The laser photonic energy will diffuse through the applied liquid to irradiate a volume of 1.0 cubic $\mathrm{mm}$. Therefore, in the periodontal pocket disinfection of a single root tooth site, the tip is applied at four sites (mesial, distal, facial, palatal), with additional application at bifurcation sites for molar teeth; each site is exposed to the fixed cycle of light emission. The cytotoxic effect will apply to both host and non-host cells, although the predominately higher number of host cells and protective presence of keratin will suitably moderate any host tissue damage (Figs 4, 5 and 6). ${ }^{48}$

The patient is advised to resume normal home care and periodontal tissue assessment can be made within 1-3 months, with repeat sessions as indicated by the presenting clinical condition (Figs 7-15).

\section{CONCLUSION}

The majority of pathologies treated in everyday general dental practice can be considered to be primary bacterial infections or are complicated by secondary bacterial contamination. Many techniques have been advocated to address the need for elimination of bacterial pathogens as part of treatment and one of the claimed advantages of surgical laser use is a bacterial reduction of target sites in both hard and soft tissue management. However, the limitations of the coaxial emission of the laser beam and difficulty in accessing all sites may compromise the desired outcome.

The use of laser photonic energy to activate an intermediate chemical and achieve bacterial destruction through secondary effect has been shown to offer advantages over surgical laser use.

Use of indocyanine green photosensitiser is seen as adjunct to the reduction of bacterial pathogens and is part of the overall treatment necessary to address causative factors and repair, remodel or restore the tissue site as required. The use of aPDT is not intended as a substitute for best practice in periodontics; patient evaluation is essential to establish aetiology, local and systemic factors and formulation of an overall and specific treatment plan. Oral hygiene instruction and scaling and root planning should be carried out and any progress quantified, using accepted treatment outcome protocols such as reduction in pocket depth, gain in clinical attachment and overall improvement in periodontal tissue appearance. Safety regulations must be applied as per national statutes and guidance and the classification of the laser defines the use of wavelength-specific $(810 \mathrm{~nm})$ protective eyewear for patient and operator.

This paper has presented the underlying principles of aPDT action and considered some of the areas of clinical treatment where indocyanine green has been shown to be of benefit.

1. Costa R A, Farah M E, Freymuller E et al. Choriocapillaris photodynamic therapy using indocyanine green. Am J Ophthalmol 2001; 132: $557-565$.

2. Huang Y-Y, Hamblin M. Dose-Response 2009; 7: 358-383.

3. Maisch T. A new strategy to destroy antibiotic resistant microorganisms: antimicrobial photodynamic treatment. Mini Rev Med Chem 2009; 9: 974-983.

4. Wilson B C; Patterson M S. The physics, biophysics, and technology of photodynamic therapy. Phys Med Bio/ 2008; 53: R61-R109.

5. Robertson C A, Hawkins E D, Abrahamse H. Photodynamic therapy (PDT): a short review on cellular mechanisms and cancer research applications for PDT. J Photochem Photobiol B 2009; 96: 1-8.

6. Bonnett R. Chemical aspects of photodynamic therapy. pp 23-30. Amsterdam: Gordon and Breach Science Publishers, 2000

7. Tunér J, Hode L. The difficult dose and intensity: treatment dose. In Laser therapy: clinical practice and scientific background. p 320. Grängesberg, Sweden: Prima Books AB, 2002.

8. Gomer C J, Luna M, Ferrario A, Wong S, Fisher A M, Rucker N. Cellular targets and molecular responses associated with photodynamic therapy. J Clin Laser

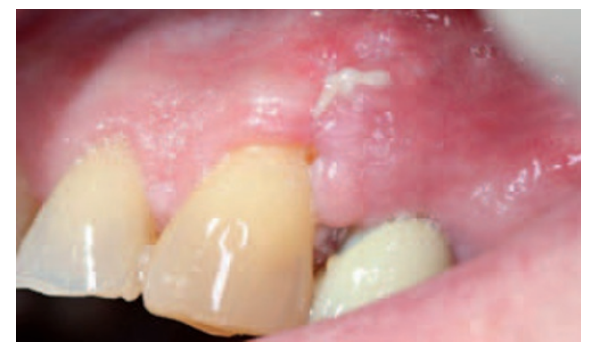

Fig. 13 Healing at 10 days

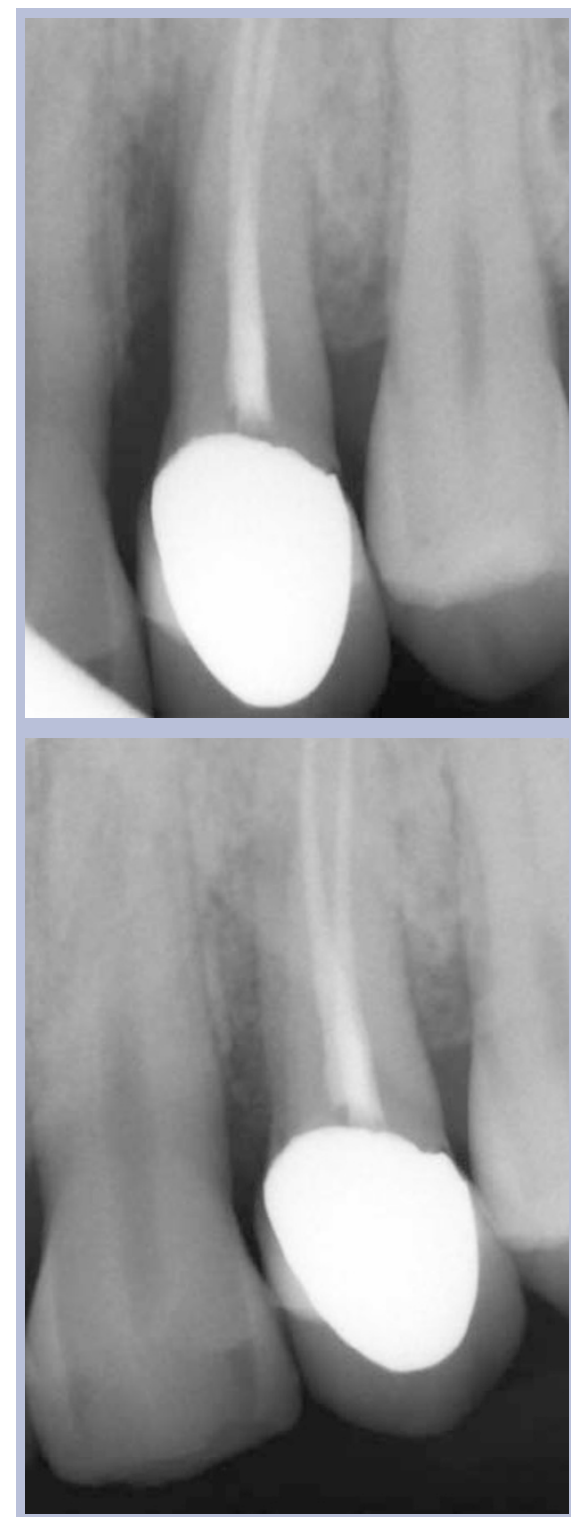

Fig. 14 Periapical radiographs showing original periodontal lesion (top) and posttreatment grafting procedure (bottom)

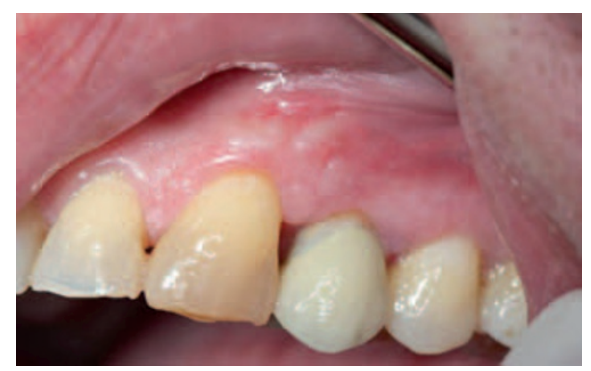

Fig. 15 Healing at 3 months 
Med Surg 1996; 14: 315-321.

9. Takasaki A, Aoki A, Mizutani K et al. Application of antimicrobial photodynamic therapy in periodonta and peri-implant diseases. Periodontol 2000 2009; 51: 109-140.

10. Mishra A, Behera R, Behera P et al. Cyanines during the 1990s: a review. Chem Rev 2000; 100: 1973-2011.

11. Desmetre T, Devoisselle J M, Mordon S. Fluorescence properties and metabolic features of indocyanine green (ICG) as related to angiography. Surv Ophthalmol 2000; 45: 15-27.

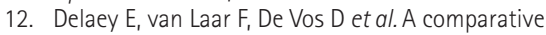
study of the photosensitizing characteristics of some cyanine dyes. J Phys Chem B 2000; 55: 27-36.

13. Bashkatov A N, Genina E A, Kochubey V I, Tuchin VV. Optical properties of human skin, subcutaneous and mucous tissues in the wavelength range from 400 to $2000 \mathrm{~nm}$. J Phys D Appl Phys 2005; 38: 2543-2555.

14. Omar G, Wilson $M$, Nair S. Lethal photosensitization of wound-associated microbes using indocyanine green and near-infrared light. BMC Microbio/2008; 8: 111.

15. Krespi Y, Kizhner V. Phototherapy for chronic rhinosinusitis. Lasers Surg Med 2011; 43: 187-191.

16. Hongcharu W, Taylor C et al. Topical ALAphotodynamic therapy for the treatment of acne vulgaris. J Invest Dermato/ 2000; 115: 183-192.

17. Tuchin V. Genina E et al. A pilot study of ICG laser therapy of acne vulgaris: photodynamic and photothermolysis treatment. Lasers Surg Med 2003; 33: 296-310.

18. Genina E, Bashkatov A, Simonenko G et al. Low-intensity indocyanine-green lase phototherapy of acne vulgaris: pilot study. J Biomedi Opt 2004; 9: 828-834.

19. Engel E, Schraml R, Maisch T et al., Light-induced decomposition of indocyanine green. Invest Ophthalmol Vis Sci 2008; 49: 1777-1783.

20. George $\mathrm{S}$, Hamblin M, Kishen A. Uptake pathways of anionicand cationic photosensitizers into bacteria. Photochem Photobiol Sci 2009; 8: 788-795.

21. Maisch T, Szeimies R M, Jori G, Abels C. Antibacterial photodynamic therapy in dermatology. Photochem Photobiol Sci 2004; 3: 907-917.

22. Genina $E A$, Bashkatov $A N$, Simonenko $G V$, Odoevskaya O D, Tuchin V V, Altshuler G B. Lowintensity indocyanine green laser phototherapy of acne vulgaris: pilot study. J Biomed Opt 2004; 9: $828-834$

23. Topaloglu N, Gulsoy M, Yuksel S. Antimicrobial photodynamic therapy of resistant bacterial strains by indocyanine green and $809 \mathrm{~nm}$ diode laser. Photomed Laser Surg 2013; 31: 155-162.

24. Braun A, Dehn C, Krause F, Jepsen S. Shortterm clinical effects of adjunctive antimicrobial photodynamic therapy in periodontal treatment: a randomized clinical trial. J Clin Periodontol 2008; 35: 877-884.

25. Konopka K, Goslinski T. Photodynamic therapy in dentistry. J Dent Res 2007; 86: 694-707.

26. Hayek R, Araújo N, Gioso M et al. Comparative study between the effects of photodynamic therapy and conventional therapy on microbial reduction in ligature-induced periimplantitis in dogs. J Periodontol 2005; 76: 1275-1281.

27. Walsh $\sqcup$. The current status of laser applications in dentistry. Aust Dent J 2003; 48: 146-155.

28. Cappuyns I, Cionca N, Wick P, Giannopoulou C, Mombelli A. Treatment of residual pockets with photodynamic therapy, diode laser, or deep scaling. A randomized, split-mouth controlled clinical trial. Lasers Med Sci 2012; 27: 979-986.

29. Wainwright M, Crossley K B. Methylene blue - a therapeutic dye for all seasons? J Chemother 2002: 14: 431-443.

30. Meisel P, Kocher T. Photodynamic therapy for periodontal diseases: State of the art. J Photochem Photobiol B 2005; 79: 159-170.

31. Polansky R, Haas M, Heschl A, Wimmer G. Clinical effectiveness of photodynamic therapy in the treatment of periodontitis. J Clin Periodonto/ 2009; 36: $575-580$

32. Christodoulides N, Nikolidakis D, Chondros P et al. Photodynamic therapy as an adjunct to nonsurgica periodontal treatment: a randomized, controlled clinical trial. J Periodonto/ 2008; 79: 1638-1644.

33. Andersen R, Loebel N, Hammond D, Wilson $M$. Treatment of periodontal disease by photodisinfection compared to scaling and root planing. J Clin Dent 2007; 18: 34-38.

34. de Almeida J M, Theodoro L H, Bosco A F, Nagata $\mathrm{M} J \mathrm{H}$, Oshiiwa M, Garcia V G. In vivo effect of photodynamic therapy on periodontal bone loss in dental furcations. J Periodonto/ 2008 ; 79: 1081-1088

35. Wilson, B C, Patterson M S. The physics, biophysics and technology of photodynamic therapy. Phys Med Biol 2008; 53: 61-109.

36. Akilov O E, O'Riordan K, Kosaka S, Hasan T. Photodynamic therapy against intracellular pathogens: problems and potentials. Med Laser App/2006; 21: 251-260.

37. Dai T, Huang $Y Y$, Hamblin M R. Photodynamic therapy for localized infections - state of the art Photodiagnosis Photody Ther 2009; 6: 170-188.

38. Karu T. Photobiology of low power laser effects. Health Phys 1989; 56: 691-704.

39. Mester E, Mester A F, Mester A: Biomedical effects of laser application. Lasers Surg Med 1985; 5: $31-39$

40. Obradović $R$, Kesić L, Mihailović D et al. A histologica evaluation of a low-level laser therapy as an adjunct to periodontal therapy in patients with diabetes mellitus. Lasers Med Sci 2013; 28: 19-24.

41. Makhlouf M, Dahaba M M, Tunér J, Eissa S A, Harhash T A. Effect of adjunctive low level laser therapy (LLLT) on nonsurgical treatment of chronic periodontitis. Photomed Laser Surg 2012; 30: 160-166.

42. Bashardoust Tajali S, Macdermid J C, Houghton P, Grewal R. Effects of low power laser irradiation on bone healing in animals: a meta-analysis. J Orthop Surg Res 2010; 5: 1.

43. de Souza Merli L A, de Medeiros V P, Toma L et al. The low level laser therapy effect on the remodeling of bone extracellular matrix. Photochem Photobiol 2012; 88: 1293-1301.

44. Korany N S, Mehanni S S, Hakam H M, El-Maghraby E M. Evaluation of socket healing in irradiated rats after diode laser exposure (histological and morphometric studies). Arch Oral Biol 2012; 57: 884-891.

45. Rosa A P, de Sousa L G, Regalo S C, Issa J P et al. Effects of the combination of low-level laser irradiation and recombinant human bone morphogenetic protein2 in bone repair. Lasers Med Sci 2012; 27: 971-977.

46. Hopkins J T et al. Low-level laser therapy facilitates superficial wound healing in humans: a triple-blind, sham-controlled study. J Ath/ Train 2004; 39: 223-229.

47. Yu W, Naim J O, Lanzafame R J. Effects of photostimulation on wound healing in diabetic mice. Lasers Surg Med 1997; 20: 56-63.

48. Kübler A C. Photodynamic therapy. Med Laser Appl 2005; 20: 37-45. 